\title{
ZONEAMENTO DAS ÁREAS SUSCEPTÍVEIS AOS MOVIMENTOS DE MASSA NO MUNICÍPIO DE TARRAFAL, ILHA DE SANTIAGO, CABO VERDE
}

\author{
Herculano SPÍNOLA \\ Sónia VICTÓRIA
}

\begin{abstract}
RESUMO
Este trabalho consiste numa análise dos elementos do meio natural e antrópico do Município de Tarrafal, extremo norte da Ilha de Santiago, Cabo Verde, com o objetivo de elaborar uma carta de zoneamento das áreas susceptíveis aos movimentos de massa utilizando o método AHP (Análise de Processos Hierárquica) e ferramentas de Sistemas de Informações Geográficas (SIG). O método AHP é um método de análise multicriterial baseado na ponderação ativa, ou seja, onde os diversos atributos relevantes de uma área são representados a partir de sua importância relativa. O potencial das informações abstraídas da carta de zoneamento evidencia que essa análise torna-se cada vez mais uma prática imprescindível para os estudos de instabilidade geotécnica, tendo em vista a necessidade de monitoramento de áreas sujeitas a constantes intervenções humanas. Essa carta poderá ser utilizada na tomada de decisões em nível municipal e no âmbito da defesa civil, bem como para o desenvolvimento de outros tipos de cartografia, como a de perigo e de risco.
\end{abstract}

Palavras-chave: zoneamento, movimentos de massa, susceptibilidade, AHP, Cabo Verde, Município do Tarrafal.

\section{ABSTRACT}

This study is an analysis of the natural and anthropogenic elements of the Tarrafal Municipality, located at the northern end of the Santiago Island, Cape Verde, and aims to draw a zoning map of the areas susceptible to mass movements, using the Analytic Hierarchy Process (AHP) method. The synthesis map allowed the identification of areas with higher and lower degree of susceptibility. The potential of the information obtained from the zoning map shows that this analysis is increasingly essential for geotechnical stability studies, in view of the need to monitor the areas subject to constant human intervention. The zoning map of the areas susceptible to mass movements can be used to make decisions, at the municipal level and in the context of civil defense, to develop other types of mapping, such as hazard and risk mapping.

Keywords: zoning, mass movements, susceptibility, AHP, Cape Verde, Tarrafal Municipality.

\section{INTRODUÇÃO}

Os movimentos de massa são processos dinâmicos que ocorrem à superfície, geralmente em vertentes, desencadeados pela interação de vários fatores, tais como tipo de rocha, solo, grau de fraturamento, declividade e vegetação. Esses processos fazem parte da dinâmica natural de formação do modelado terrestre, entretanto, podem se tornar um grave problema quando intensificados pela ocupação humana (SESTINI 1999). A remoção da cober- tura vegetal e/ou obras de engenharia, por exemplo, levam à exposição do solo, favorecendo esses processos em eventos de chuvas intensas.

Esses fenômenos podem ser classificados segundo o tipo de movimento, velocidade, geometria de falha, morfometria da vertente, tipo de material removido e grau de alteração, entre outros (SUARÉZ 1998 apud MUÑOZ 2005). Com relação à morfometria das vertentes, a variável declividade fornece o grau de inclinação do relevo e está diretamente relacionada à velocidade de deslocamento 
de material e à capacidade de transporte de massas sólidas e líquidas (MUÑOZ 2005).

Neste contexto, os Sistemas de Informações Geográficas (SIG) e os métodos de análise espacial são de grande importância para a identificação de áreas susceptíveis aos movimentos de massa, uma vez que permitem a integração de diferentes níveis de informações espaciais e auxiliam na elaboração de prognósticos mais completos e confiáveis da área de interesse.

O objetivo desse trabalho consistiu na elaboração de uma carta de zoneamento das áreas susceptíveis aos movimentos de massa do tipo queda de blocos para o Município de Tarrafal, Ilha de Santiago (Cabo Verde), utilizando-se o método AHP e ferramentas de SIG disponíveis no software Arc GIS 9.3.

\section{MATERIAIS E METÓDOS}

A leitura dos estudos geográficos sobre a paisagem pode estar associada a aspectos físicos e sociais. Para compreender os processos de movimento de massa foram analisados os fatores naturais intrínsecos da encosta (geologia/litologia, fraturas, declividade, solo e a cobertura vegetal) e o fator antrópico, especificamente a proximidade das vias.

Realizou-se um inventário dos dados cartográficos associados às informações alfanuméricas, que incluiu as seguintes cartas: declividade, derivada de dados topográficos (DGOTDU 2003), geologia/litologia na escala 1/25.000 (SERRALHEIRO 1976), alinhamentos tectônicos (PEREIRA et al. 2008), solos e vegetação (DINIZ \& MATOS 1986). No processo de zoneamento (Figura 1) foi utilizado o método AHP (Análise de Processos Hierarquizados), muito utilizado para esses fins (ROSA 1996). Trata-se de um método de análise multicriterial baseado na ponderação ativa, ou seja, onde os diversos atributos relevantes são representados a partir de sua importância relativa numa escala que varia de 1 a 9 (Tabela 1).

Conforme SILVA (2007), o julgamento reflete as respostas a duas perguntas: qual dos dois elementos é mais importante em relação a um critério de nível superior e com que intensidade, a partir de uma escala de importância relativa de 1 até 9 (Tabela 1).

Após o julgamento, procede-se a cálculos do peso relativo de cada uma das variáveis. Todos os resultados são submetidos ao índice de consistência (IC, Equação 1) e à razão de consistência (RC, Equação3).

$\mathrm{IC}=\lambda_{\max }-\mathrm{n} / \mathrm{n}-1$

Sendo IC $=$ Índice de Consistência, $\lambda_{\max }=$ auto valor máximo, $\mathrm{n}=$ tamanho da matriz

$\lambda_{\text {max }}$, pode ser calculado conforme a Equação 2:

$\lambda_{\text {max }}=\sum \mathrm{Xw} \times \mathrm{w}$

Onde $\mathrm{Xw}=$ total da matriz de ponderação, $\mathrm{w}=$ peso.

Como regra geral: caso o índice de consistência seja menor do que 0,1 , haverá consistência para se prosseguir com os cálculos do AHP; se maior do que 0,1 , recomenda-se novos julgamentos até que a consistência aumente.

Sugere-se também o uso da Razão de Consistência (Equação 3), que considera o IC e o Índice Randômico (IR), função do tamanho "n" da amostra (SAATY 1991).

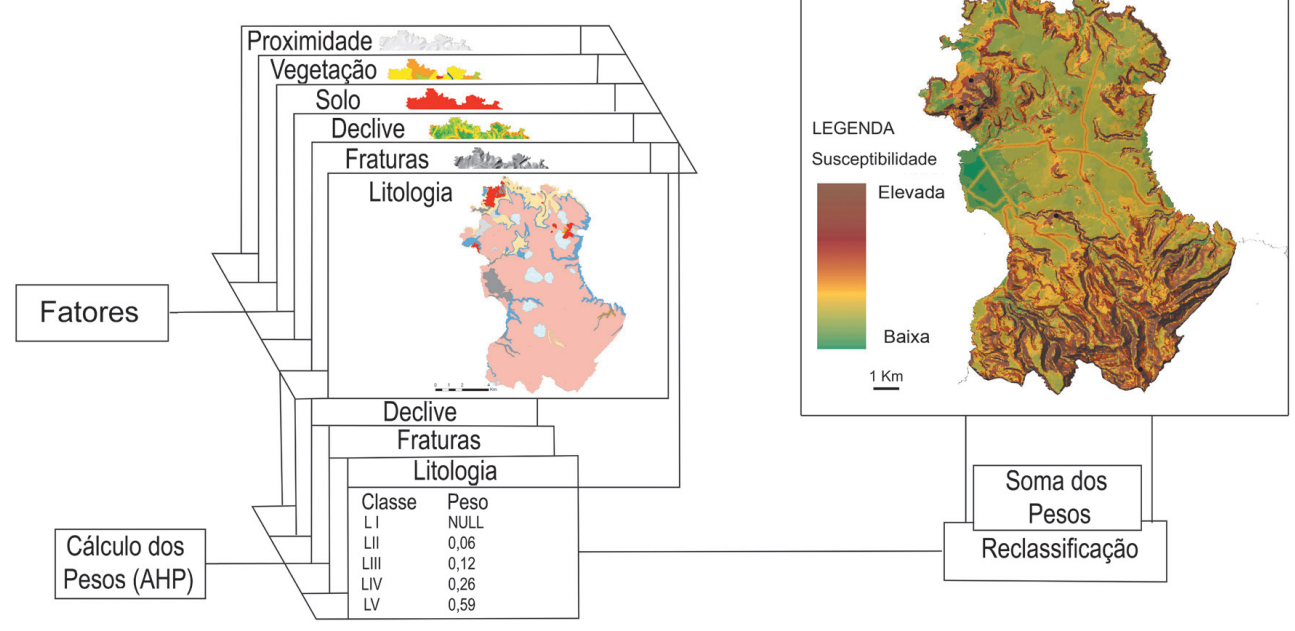

FIGURA 1 - Modelagem das áreas susceptíveis aos movimentos de massa no Município de Tarrafal. 
TABELA 1 - Definição do grau de importância relativa no método AHP.

\begin{tabular}{|c|c|c|}
\hline Importância relativa & Definição & Explicação \\
\hline 1 & Mesma importância & Duas atividades contribuem para concretizar o objetivo \\
\hline 3 & $\begin{array}{l}\text { Importância pequena de uma sobre } \\
\text { a outra }\end{array}$ & $\begin{array}{c}\text { A importância e o julgamento favorecem levemente uma } \\
\text { atividade em relação à outra }\end{array}$ \\
\hline 5 & Importância grande ou essencial & $\begin{array}{c}\text { A importância e o julgamento favorecem fortemente uma } \\
\text { atividade em relação à outra }\end{array}$ \\
\hline 7 & $\begin{array}{l}\text { Importância muito grande ou } \\
\text { demonstrada }\end{array}$ & $\begin{array}{l}\text { Uma atividade é muito fortemente favorecida em relação à } \\
\text { outra, sua dominação de importância é demonstrada na prática }\end{array}$ \\
\hline 9 & Importância absoluta & $\begin{array}{c}\text { A evidência favorece uma atividade em relação à outra com o } \\
\text { mais alto grau de certeza }\end{array}$ \\
\hline $2,4,6,8$ & $\begin{array}{l}\text { Valores intermédios entre valores } \\
\text { adjacentes }\end{array}$ & $\begin{array}{l}\text { Quando se procura uma condição de compromisso } \\
\text { entre duas definições }\end{array}$ \\
\hline
\end{tabular}

Fonte: SAATY (1991)

$\mathrm{RC}=\mathrm{IC} / \mathrm{IR}$

(Eq. 3)

Onde: $\mathrm{RC}=$ Razão de Consistência, IC = Índice de Consistência, IR = Índice Randômico.

O mesmo autor propõe uma tabela com os índices randômicos (IR) de matrizes de ordem 1 até 15 (Tabela 2).

O cruzamento dos diversos fatores foi realizado em ambiente de Sistema de Informações Geográficas (SIG) no software Arc GIS 9.3.

A partir do zoneamento das áreas susceptíveis aos movimentos de massa, foi possível checar em campo as áreas mais críticas do Município de Tarrafal.

\section{CONTEXTO GEOGRÁFICO DO MUNICÍPIO DO TARRAFAL}

As ilhas de Cabo Verde estão localizadas no Atlântico Central, entre o Trópico de Câncer e o Equador. Limitam-se pelos paralelos $17^{\circ} 13^{\prime}$ (Ponta Cais dos Fortes Santo Antão) e $14^{\circ} 48^{\prime}$ (Ponta Nho Martinho, Brava) de latitude Norte e pelos meridianos $22^{\circ} 42^{\prime}$ (Ilhéu Baluarte, Boavista) e $25^{\circ} 22^{\prime}$ (Ponta Chã de Mangrado, Santo Antão) de longitude Oeste de Greenwich (Figura 2).

A Ilha de Santiago localiza-se na região sul do país e integra uma das quatro ilhas do Sotavento. O Município de Tarrafal situa-se no extremo norte da ilha e confronta-se a sudeste com o Município de São Miguel e a sudoeste com o Município de Santa Catarina. Ocupa uma área de $112,4 \mathrm{~km}^{2}$ e conta, atualmente, com 18.565 habitantes distribuídos em 20 zonas do município. A cidade do Tarrafal e a localidade de Chão Bom, os dois principais núcleos populacionais do município, apresentam características básicas de uma pequena cidade, mas com elevado grau de ruralidade, e concentram a maior parte da população.

A rede hidrográfica do Município de Tarrafal segue os alinhamentos estruturais de direções NNW-SSE e N-S; nas regiões de cones piroclásticos o padrão de drenagem é radial. A rede de drenagem é mais desenvolvida nos quadrantes $\mathrm{N}$ e NW.

Em geral, o clima do Município de Tarrafal é do tipo árido, contudo, pode-se diferenciar as seguintes zonas climáticas (AMARAL 1964) (Figura 3):

- Árido: na faixa litorânea em altitudes inferiores a $200 \mathrm{~m}$;

- Semiárido: nas áreas com altitudes superiores a $200 \mathrm{~m}$ e inferior a $400 \mathrm{~m}$;

- Subúmido: nas áreas com altitudes entre 400 até $700 \mathrm{~m}$;

- Úmido: nas áreas com altitude mínima de 700 m e máxima de $1063 \mathrm{~m}$.

A temperatura média anual no Município é de $25^{\circ} \mathrm{C}$.

TABELA 2 - Índices randômicos médios do AHP

\begin{tabular}{cccccccccccccccccccc}
\hline 1 & 2 & 3 & 4 & 5 & 6 & 7 & 8 & 9 & 10 & 11 & 12 & 13 & 14 & 15 \\
\hline 0,00 & 0,00 & 0,58 & 0,90 & 1,12 & 1,24 & 1,32 & 1,41 & 1,45 & 1,49 & 1,51 & 1,48 & 1,56 & 1,57 & 1,59 \\
\hline
\end{tabular}

Fonte: SAATY (1991) 


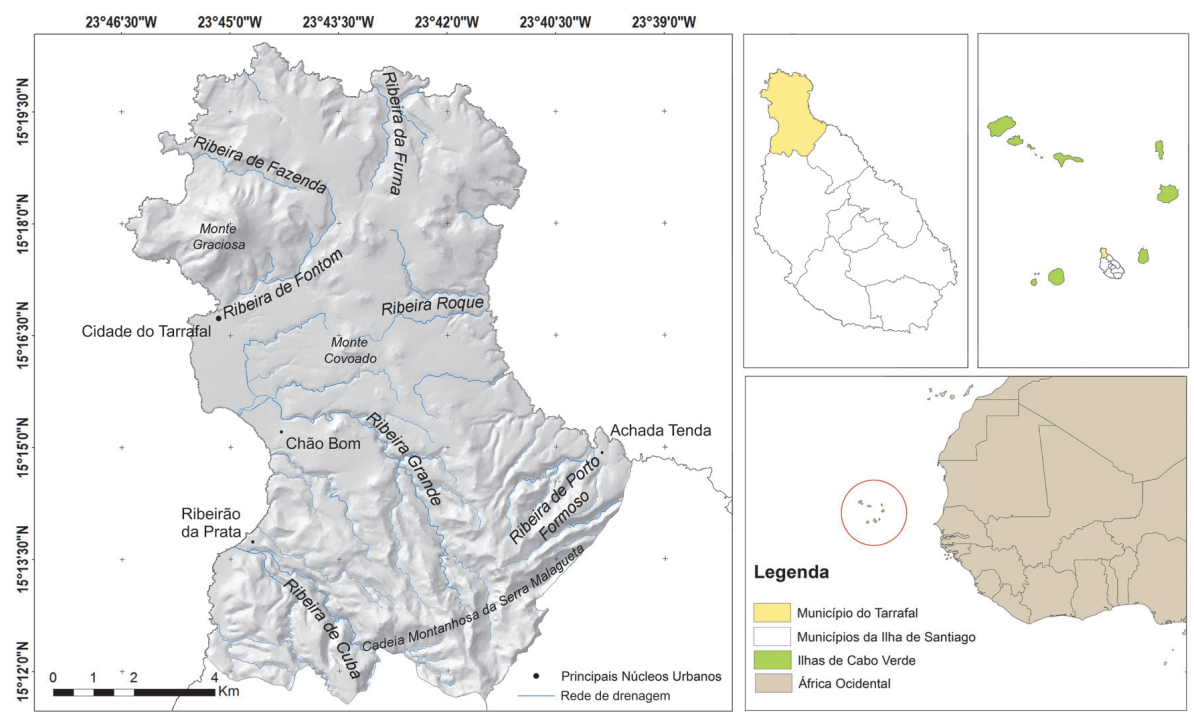

FIGURA 2 - Contexto geográfico do Município do Tarrafal.

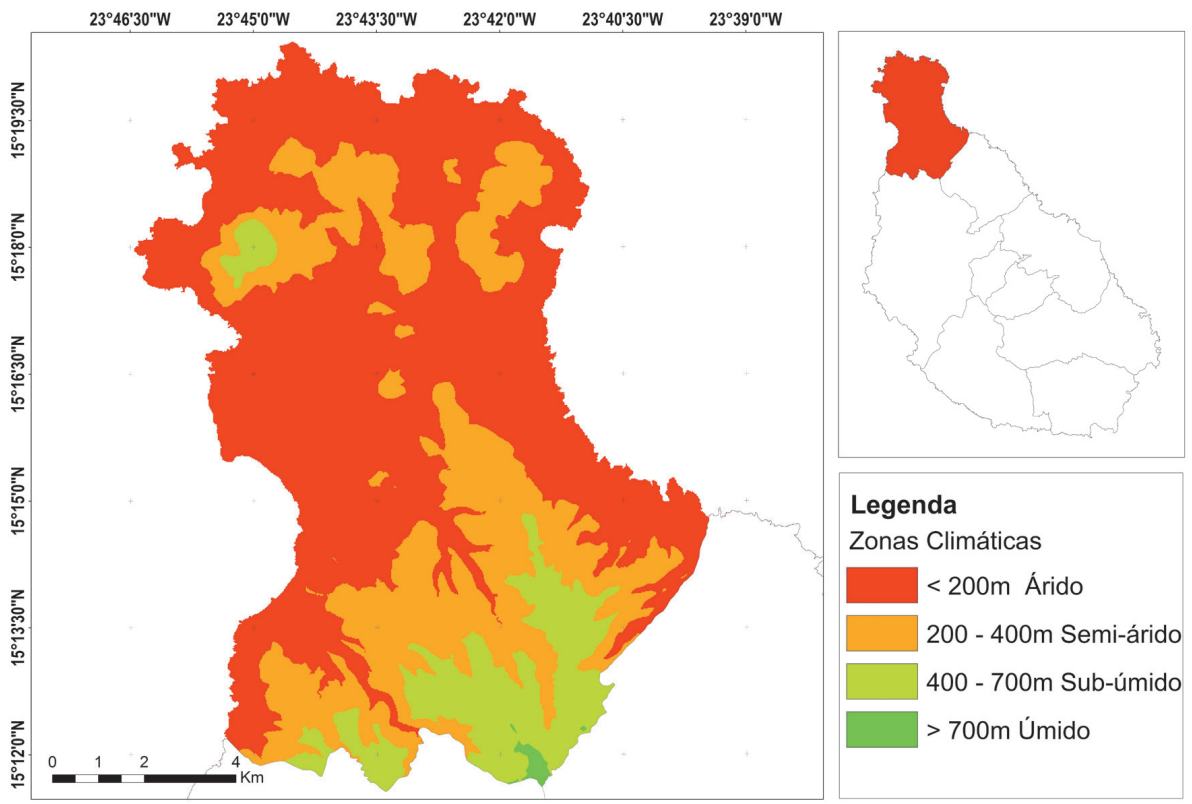

FIGURA 3 - Zoneamento climático do Município do Tarrafal.

As chuvas distribuem-se de forma bastante irregular e apresentam um contraste entre as zonas altas e as litorâneas, caracterizado por duas estações bem definidas:

- estação das chuvas ou "das águas" (agosto a outubro): período de chuvas irregulares intimamente ligado às migrações da Zona de Convergência Intertropical;

- estação seca ou "das brisas" (dezembro a junho, mais típica entre março e junho): é a estação mais fresca e seca, com predominância da ação dos ventos alísios de nordeste que, de maneira geral, sopram todo o ano.

\section{CARACTERIZAÇÃO E PONDERAÇÃO DAS VARIÁVEIS SEGUNDO O MÉTODO AHP}

No contexto da avaliação de riscos geomorfológicos e, particularmente, no caso dos movimentos de massa, pode-se entender por susceptibilidade a 
probabilidade espacial da ocorrência de um determinado fenômeno numa determinada área com base nos fatores condicionantes do terreno, independentemente do seu período de recorrência (GARCIA \& ZÊZERE 2003).

Conforme o enfoque e a disponibilidade de dados, as variáveis consideradas são as geológicas, geomorfológicas, climáticas, geotécnicas, pedológicas, fitológicas e antrópicas (estas, em particular, relacionadas ao uso e cobertura do solo). Deve-se salientar que essas variáveis atuam de forma interativa e, portanto, não devem ser analisadas isoladamente. A seguir são descritas as características e o comportamento de cada variável relacionada com os processos de movimentos de massa gravitacionais, segundo o método AHP.

\subsection{Geologia/Litologia}

Os condicionantes geológicos considerados no estudo foram litologia e as características estruturais da área. O tipo de rocha define a permeabilidade e, consequentemente, os padrões texturais e da rede de drenagem, além da resistência ao intemperismo. A presença de fraturas indica de descontinuidades e áreas de menor resistência, constituindo caminhos preferenciais para a erosão e os movimentos de massa.

De acordo com as características geotécnicas dos litotipos, foi feito um agrupamento dos mesmos, baseado nos estudos de SERRALHEIRO (1976). Os seguintes litotipos foram identificados no Município de Tarrafal (Figura 4, Tabela 3):

- Basaltos e brechas antigos e conglomerados: basaltos e brechas antigos ocorrem de forma dispersa, principalmente no farol de Ponta Preta, Chã de Arruela e Baía de Angra e como um pequeno afloramento na Baía de Angra; conglomerados são observados como pequenos retalhos nas regiões de Ponta Bicuda e Ponta Preta, no litoral, nas escarpas do mar do Tarrafal, na Ribeira e na Ponta Laje Grande;

- Basaltos subaéreos e submarinos (basaltos, fonólitos e traquitos): compreendem fácies terrestre (piroclastos e basaltos subaéreos) e marinho (basaltos submarinos intercalados com calcários e calcarenitos). Os basaltos submarinos são observados ao longo do litoral nas porções oriental e na localidade de Chão Bom, em afloramentos às margens da Ribeira de Fontom e também no norte do município;

- Piroclastos: ocorrem como cones piroclásticos, que formam o Monte Achada Grande, Monte Covoado, Monte Vermelho e Monte Costa;

- Depósitos de vertente: Material não consolidado, resultante dos agentes do intemperismo, normalmente encontrado no sopé das vertentes de inclinação elevada. Ocorrem nas regiões da pedra n'Pena, no Ribeirão da Fazenda e em pequenos afloramentos no sudoeste do município.

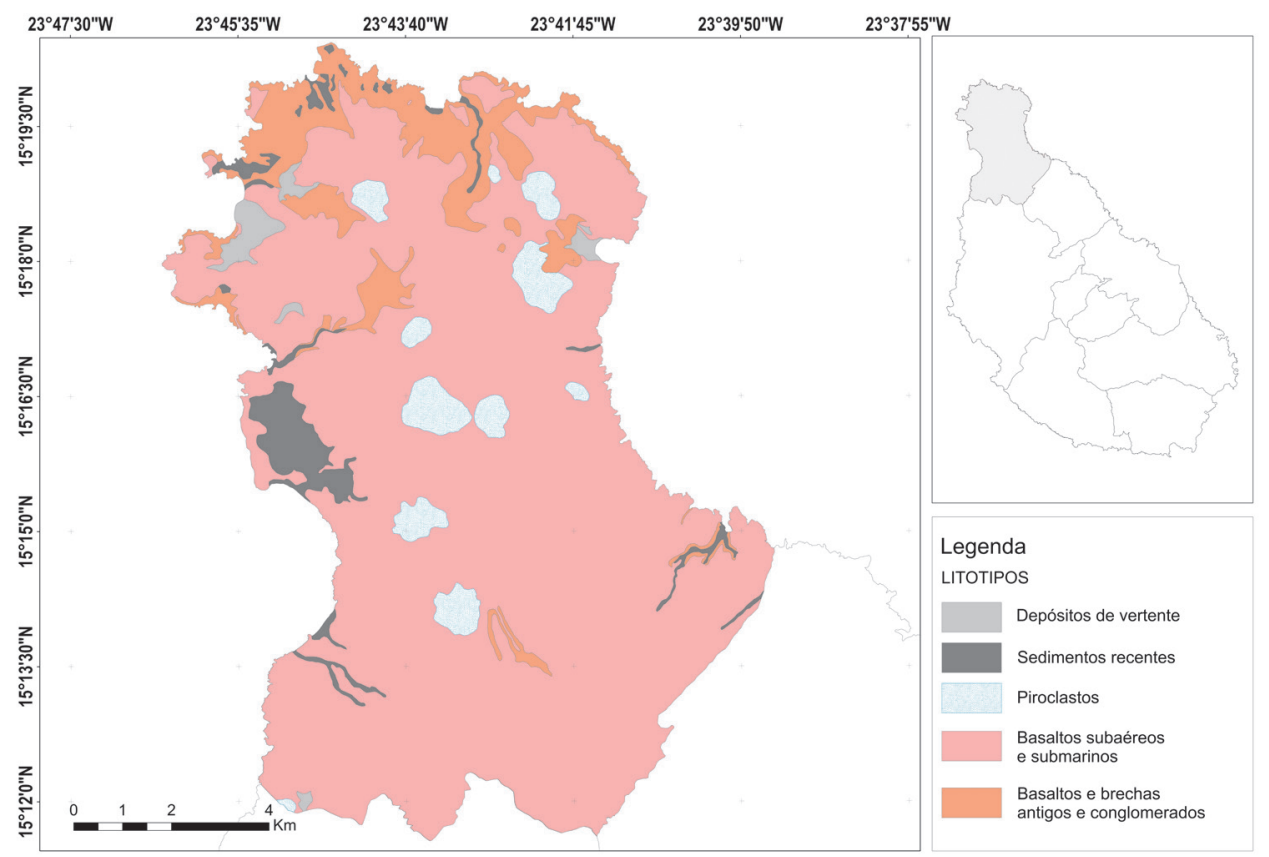

FIGURA 4 - Carta litológica simplificada do Município do Tarrafal (Modificado de SERRALHEIRO 1976). 
TABELA 3 - Representatividade das classes litológicas do Município do Tarrafal.

\begin{tabular}{cccc}
\hline Classes & Litologia & Area $\left(\mathrm{km}^{2}\right)$ & Representatividade $(\%)$ \\
\hline L I & Sedimentos Recentes & 4,54 & 3,76 \\
L II & Depósitos de Vertente & 1,63 & 1,32 \\
L III & Basaltos e brechas antigos e conglomerados & 11,53 & 9,54 \\
L IV & Piroclastos & 5,47 & 4,52 \\
L V & Basaltos subaéreos e submarinos & 97,73 & 80,84 \\
\hline
\end{tabular}

TABELA 4 - Ponderação AHP em função do fator litológico.

\begin{tabular}{|c|c|c|c|c|c|c|c|c|c|c|}
\hline Classes & Litologia & $L I$ & $L I I$ & $L I I I$ & $L I V$ & $L V$ & & & & \\
\hline L I & Sedimentos recentes & - & - & - & - & - & & & & \\
\hline L II & Depósitos de Vertente & - & 1,00 & 0,33 & 0,20 & 0,14 & & & & \\
\hline L III & $\begin{array}{c}\text { Basaltos e brechas antigos } \\
\text { e conglomerados }\end{array}$ & - & 3,00 & 1,00 & 0,33 & 0,20 & & & & \\
\hline L IV & Piroclastos & - & 5,00 & 3,00 & 1,00 & 0,33 & & & & \\
\hline L V & $\begin{array}{c}\text { Basaltos subaéreos e } \\
\text { submarinos }\end{array}$ & - & 7,00 & 5,00 & 3,00 & 1,00 & & & & \\
\hline \multirow[t]{2}{*}{$X w$} & & - & 16,00 & 9,33 & 4,53 & 1,68 & & & & \\
\hline & & $L I$ & $L I I$ & $L I I I$ & $L I V$ & $L V$ & Total & $w$ & $\lambda \operatorname{Max}$ & Estabilidade \\
\hline L I & Sedimentos recentes & - & - & - & - & - & - & - & \multirow[b]{6}{*}{4,18} & - \\
\hline L II & Depósitos de vertente & - & 0,06 & 0,04 & 0,04 & 0,09 & 0,23 & 0,06 & & Baixa \\
\hline L III & $\begin{array}{c}\text { Basaltos e brechas antigos } \\
\text { e conglomerados }\end{array}$ & - & 0,19 & 0,11 & 0,07 & 0,12 & 0,49 & 0,12 & & $\begin{array}{l}\text { Baixa } \\
\text { moderada }\end{array}$ \\
\hline L IV & Piroclastos & - & 0,31 & 0,32 & 0,22 & 0,20 & 1,05 & 0,26 & & Moderada \\
\hline \multirow[t]{2}{*}{ L V } & $\begin{array}{c}\text { Basaltos subaéreos e } \\
\text { submarinos }\end{array}$ & - & 0,44 & 0,54 & 0,66 & 0,60 & 2,23 & 0,56 & & Elevada \\
\hline & & - & 1,00 & 1,00 & 1,00 & 1,00 & 4,00 & & & \\
\hline
\end{tabular}

- Sedimentos recentes: areias e cascalheiras das praias, depósitos de enxurrada, calcários e dunas fósseis; ocorrem em vários locais, como em Chão Bom e Baía Verde.

Considerando as propriedades litológicas intrínsecas de cada classe foi atribuído um peso relativo a cada uma (Tabela 4), obedecendo aos critérios do método AHP. Os litotipos da classe L II apresentam menor estabilidade, ou seja, são mais propensos a movimentos de massa em relação às demais classes.

Os aluviões e as dunas foram excluídos da análise, uma vez que não são afetados por movimentos de massa em vertente.

\subsubsection{Alinhamentos tectônicos}

O mapeamento dos alinhamentos tectônicos é fundamental na identificação de áreas que apresentam maior susceptibilidade a movimentos de mas- sa. Nas zonas situadas a nordeste do Monte Covoado e nas regiões de Guindão e da caldeira de Maria Sevilha observam-se sistemas de falhas ou fraturas na direção NE-SW. As fraturas de direção NW-SE ocorrem em todo o território municipal, mas com maior densidade na porção NE do Monte Graciosa. As zonas com maior densidade de fraturas estão associadas às zonas montanhosas e algumas áreas de cones piroclásticos (Figura 5, Tabela 5).

\subsection{Declividade}

A declividade é uma variável essencial na análise da estabilidade, uma vez que seu incremento aumenta a tensão cisalhante e, consequentemente, favorece a ocorrência dos movimentos de massa. Elevada inclinação das encostas traduz-se também em baixa espessura dos solos (GARCIA 2004 apud CORONADO 2006). O relevo do Mu- 


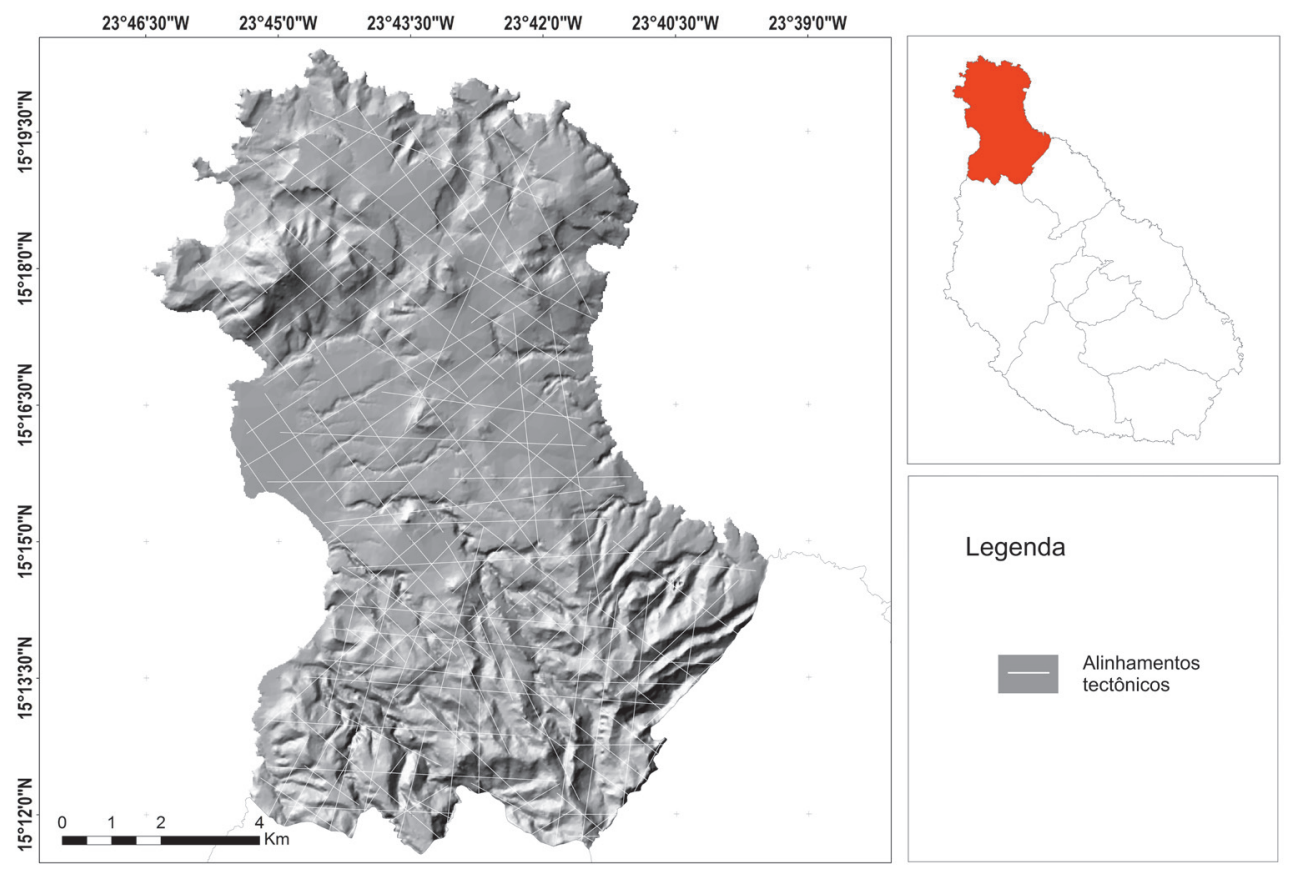

FIGURA 5 -Sistemas de fraturas identificadas no Município do Tarrafal (Extraído de PEREIRA et al. 2008).

TABELA 5 - Ponderação AHP em função do fator densidade de fraturas.

\begin{tabular}{|c|c|c|c|c|c|c|c|}
\hline Densidade & Elevada & Moderada & Baixa & & & & \\
\hline Elevada & 1,00 & 3,00 & 5,00 & & & & \\
\hline Moderada & 0,33 & 1,00 & 2,00 & & & & \\
\hline Baixa & 0,20 & 0,50 & 1,00 & & & & \\
\hline$X w$ & 1,53 & 4,50 & 8,00 & & & & \\
\hline Densidade & & & & Total & $w$ & $\lambda \max$ & Susceptibilidade \\
\hline Elevada & 0,65 & 0,67 & 0,63 & 1,95 & 0,65 & & Elevada \\
\hline Moderada & 0,22 & 0,22 & 0,25 & 0,69 & 0,23 & & Moderada \\
\hline Baixa & 0,13 & 0,11 & 0,13 & 0,37 & 0,12 & & Baixa \\
\hline Total & 1,00 & 1,00 & 1,00 & 3,00 & 1,00 & 3,01 & \\
\hline
\end{tabular}

$I C=\lambda \max -n / n-1 \rightarrow I C=3,01-3 / 3-1 \rightarrow I C=0,01 / 2 \rightarrow I C=0,005$

$I R=I C / C A \rightarrow I R=0,005 / 0,58 \rightarrow I R=0,086 \rightarrow I R=8,6 \%$

nicípio do Tarrafal é diversificado em relação as formas de relevo: o relevo é montanhoso a sul e suaviza no sentido norte, embora apresente algumas elevações, tais como o Monte Covoado, Monte Graciosa e o Monte Costa. A altitude média é de cerca de $150 \mathrm{~m}$; o Monte Graciosa, com uma cota de $645 \mathrm{~m}$, constitui a maior elevação da região e a terceira maior da Ilha de Santiago (Figura 6). O ponto mais alto do município, com cota aproxima- da de $800 \mathrm{~m}$, situa-se nas proximidades do maciço de Serra Malagueta.

Na porção sul do Município de Tarrafal a declividade é, em geral, superior a $20 \%$, enquanto ao norte é inferior a $20 \%$; as escarpas, predominantes na região sul, atingem valores de declividade superiores a 50\% (Figura 7). Na ponderação AHP (Tabela 6), áreas com declividade inferior a $10 \%$ são as menos susceptíveis a movimentos de massa. 


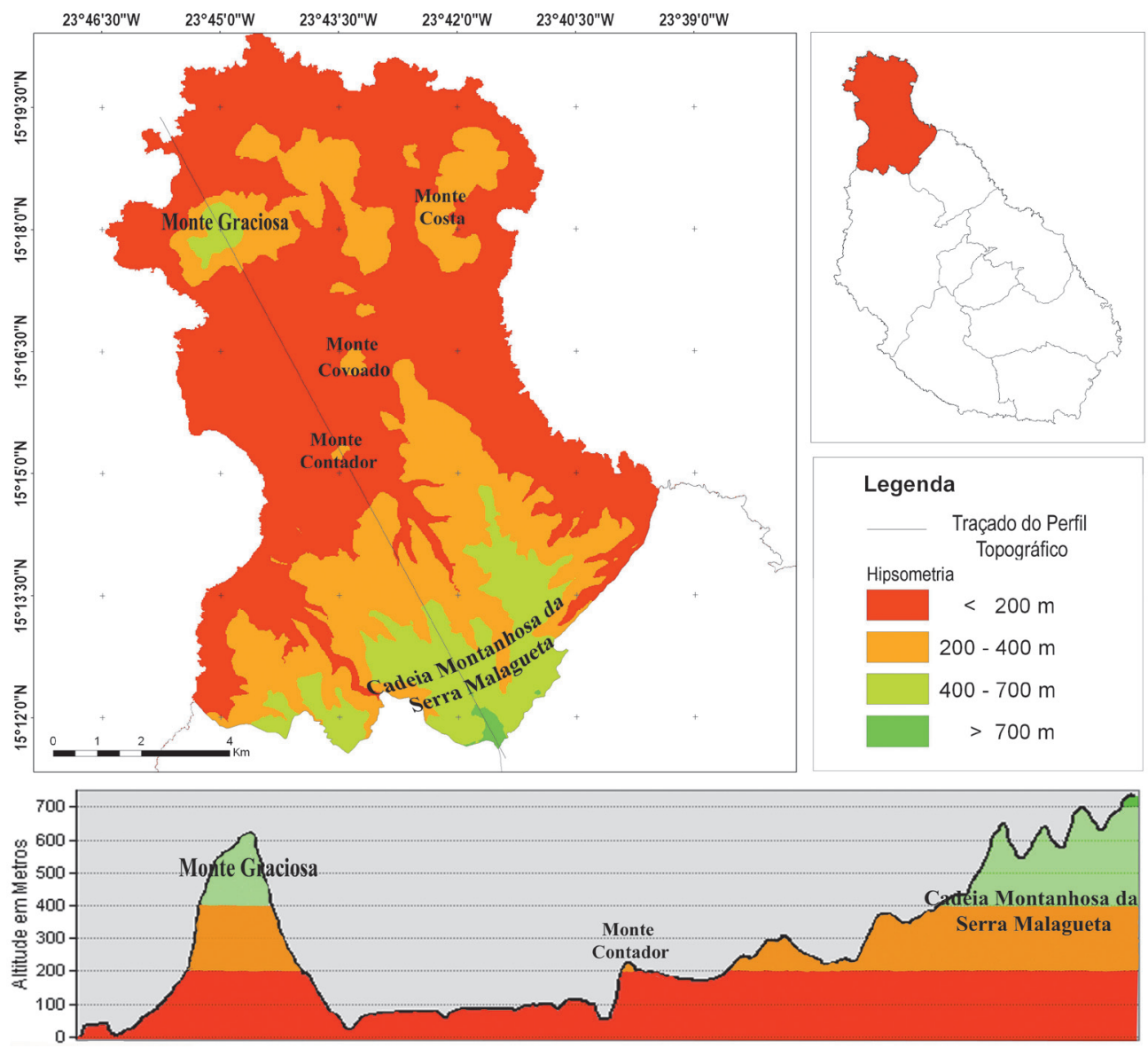

FIGURA 6 - Carta hipsométrica e perfil topográfico (NW-SE) do Município de Tarrafal.
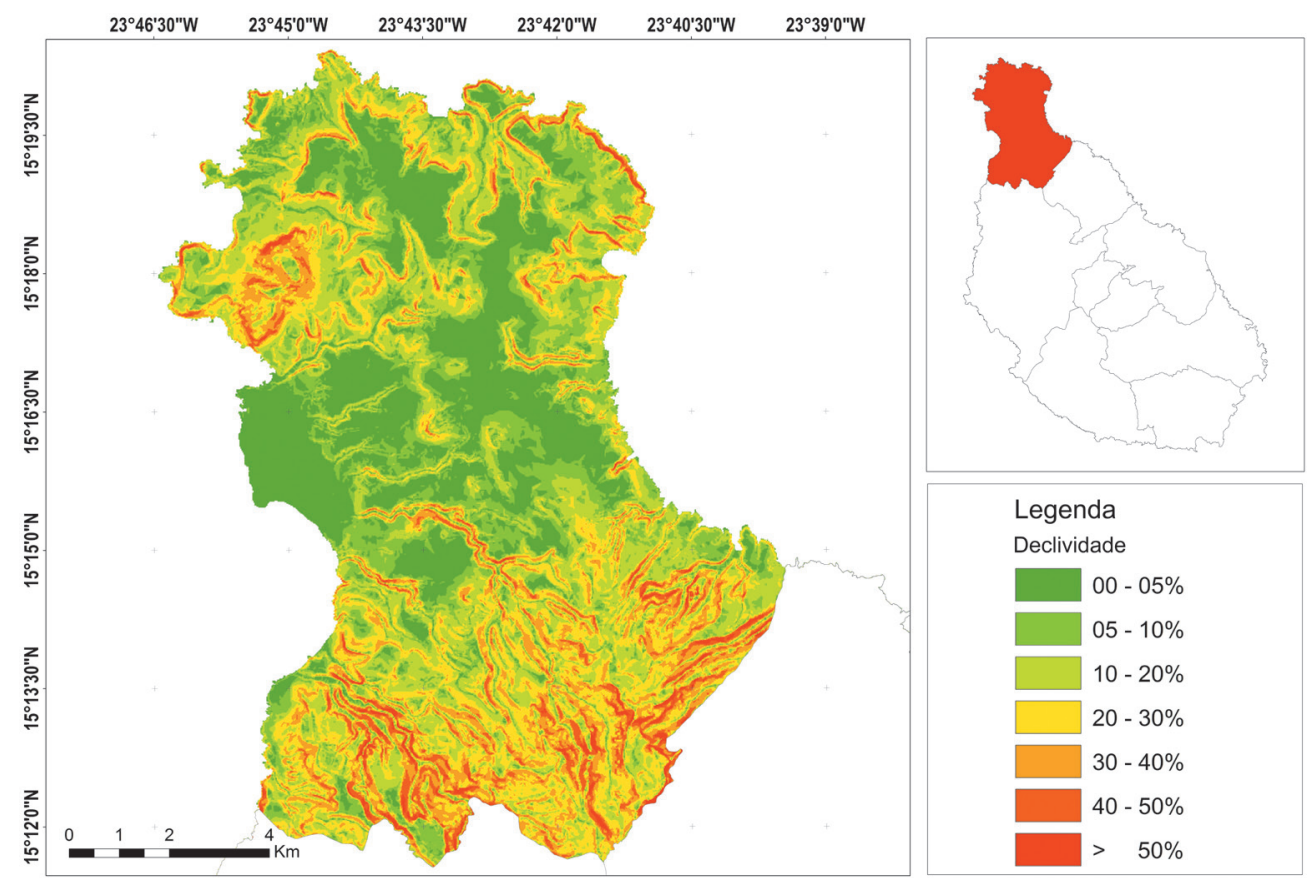

FIGURA 7 - Carta de declividade (\%) do Município de Tarrafal. 
TABELA 6 - Ponderação AHP em função das classes de declividade.

\begin{tabular}{|c|c|c|c|c|c|c|c|c|c|}
\hline Declividade \% & $<10$ & 20 & 30 & 40 & $50 />50$ & & & & \\
\hline$<10$ & 1 & 0,33 & 0,20 & 0,14 & 0,11 & & & & \\
\hline 20 & 3 & 1 & 0,50 & 0,20 & 0,14 & & & & \\
\hline 30 & 5 & 2 & 1 & 0,50 & 0,20 & & & & \\
\hline 40 & 7 & 5 & 2 & 1 & 0,50 & & & & \\
\hline 50 & 9 & 7 & 5 & 2 & 1 & & & & \\
\hline$X w$ & 25 & 15,33 & 8,70 & 3,84 & 1,95 & & & & \\
\hline Declividade \% & & & & & & Total & $w$ & $\lambda \max$ & Estabilidade \\
\hline$<10$ & 0,04 & 0,02 & 0,02 & 0,04 & 0,06 & 0,18 & 0,04 & & Muito elevada \\
\hline 20 & 0,12 & 0,07 & 0,06 & 0,05 & 0,07 & 0,37 & 0,07 & & Elevada \\
\hline 30 & 0,2 & 0,13 & 0,11 & 0,13 & 0,10 & 0,68 & 0,14 & & Moderada \\
\hline 40 & 0,28 & 0,33 & 0,23 & 0,26 & 0,26 & 1,35 & 0,27 & & Baixa Moderada \\
\hline $50 />50$ & 0,36 & 0,46 & 0,57 & 0,52 & 0,51 & 2,42 & 0,48 & & Baixa \\
\hline Total & 1,00 & 1,00 & 1,00 & 1,00 & 1,00 & 5,00 & 1,00 & 5,19 & \\
\hline
\end{tabular}

$I C=\lambda \max -n / n-1 \rightarrow I C=5,19-1 \rightarrow I C=0,19 / 4 \rightarrow I C=0,047$

$I R=I C / I R \rightarrow I R=0,19 / 1,12 \rightarrow I R=0,042 \rightarrow I R=4,2 \%$

\subsection{Solos}

Os solos da Ilha de Santiago desenvolvem-se a partir de rochas vulcânicas e caracterizam-se pela predominância de solos pouco espessos e acentuada pedregosidade (OLIVEIRA 2011). Os solos expostos sobre formações basálticas, sem cobertura vegetal, são impermeáveis e favorecem o escoamento superficial (SABINO 1991).

Em estudo recente na área deste trabalho, DINIZ \& MATOS (1986) identificaram os seguintes tipos de solos (Figura 8):

- Litossolos: solos pouco espessos $(<20 \mathrm{~cm})$ sobre substrato consolidado de basaltos, fonólitos ou traquitos, em geral, com bastante material pedregoso;

- Regossolos: solos incipientes constituídos por materiais não consolidados e, em geral, apresentam grande espessura. Relacionam-se com materiais não consolidados, como areias de praia e piroclastos dos cones vulcânicos;

- Fluvissolos êutricos: solos de origem aluvionar, composição granulométrica muito variável, com predomínio de texturas médias (franco a franco-arenoso), em geral, com elevada percentagem de elementos grossos (cascalho, calhaus e blocos); os Fluvissolos êutricos de origem coluvionar, que ocupam mais frequentemente fundos de vale (terraços e acumulações de sopés de vertente), caracte- rizam-se também pela textura muito variável e pela elevada percentagem de elementos grossos. Devese salientar, todavia, que são frequentes os casos de terraços recobertos por camada mais ou menos espessa de materiais finos (silte e argila);

- Cambissolos êutricos: solos de textura fina ou média (franco ou franco-argilosos), pouco espessos, com um horizonte Bc (câmbico) bem expressivo e um horizonte de alteração da rocha-mãe (C) razoavelmente desenvolvido; os cambissolos líticos são menos espessos que os cambissolos êutricos, com horizonte $\mathrm{Bc}$ pouco desenvolvido, em contato com a rocha subjacente (em geral, basaltos ou fonólito) a pouca profundidade. Associam-se normalmente a afloramentos rochosos e possuem elevada proporção de elementos pedregosos; tal como os litossolos, ocorrem em áreas sujeitas a intensa atividade erosiva;

- Xerossolos: solos de textura fina (argilo-siltosos ou argilosos), geralmente pouco profundos (espessura entre 30 e $50 \mathrm{~cm}$ ), pardos ou avermelhados, estruturados.

Considerando as características dos solos, a ponderação feita utilizando o método AHP (Tabela 7) mostra que a classe dos Xerossolos é a mais propensa ao desencadeamento de movimentos de massa. Os fluvissolos foram excluídos da análise por não serem afetados por movimentos de massa. 


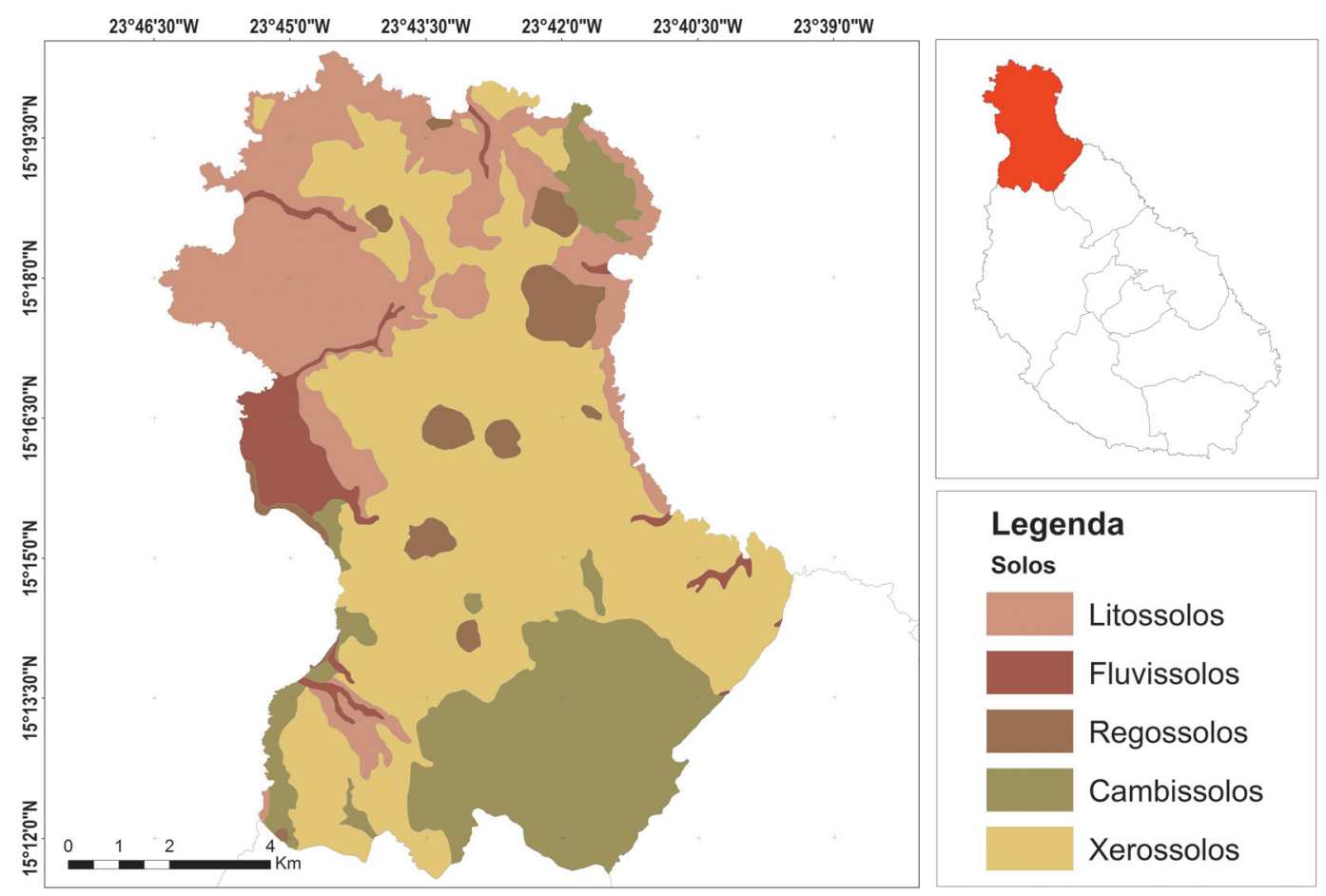

FIGURA 8 - Carta de solos do Município do Tarrafal (Extraído de DINIZ \& MATOS 1986).

TABELA 7 - Ponderação AHP em função do fator solo.

\begin{tabular}{|c|c|c|c|c|c|c|c|c|c|c|}
\hline Classes & Solos & $S I$ & $S I I$ & SIII & $S I V$ & $S V$ & & & & \\
\hline$S I$ & Fluvissolos & - & - & - & - & - & & & & \\
\hline$S I I$ & Litossolos & - & 1,00 & 3,00 & 5,00 & 7,00 & & & & \\
\hline SIII & Regossolos & - & 0,33 & 1,00 & 3,00 & 5,00 & & & & \\
\hline$S I V$ & Cambissolos & - & 0,20 & 0,33 & 1,00 & 3,00 & & & & \\
\hline$S V$ & Xerossolos & - & 0,14 & 0,20 & 0,33 & 1,00 & & & & \\
\hline \multirow[t]{2}{*}{$X w$} & & & 1,68 & 4,53 & 9,33 & 16,00 & & & & \\
\hline & & $S I$ & SII & SIII & $S I V$ & $S V$ & Total & $w$ & $\lambda \operatorname{Max}$ & Estabilidade \\
\hline$S I$ & Fluvissolos & - & - & - & - & - & - & - & - & - \\
\hline SII & Litossolos & - & 0,60 & 0,66 & 0,54 & 0,44 & 2,23 & 0,56 & & Elevada \\
\hline SIII & Regossolos & - & 0,20 & 0,22 & 0,32 & 0,31 & 1,05 & 0,26 & & Moderada \\
\hline$S I V$ & Cambissolos & - & 0,12 & 0,07 & 0,11 & 0,19 & 0,49 & 0,12 & & Baixa moderada \\
\hline \multirow[t]{2}{*}{$S V$} & Xerossolos & - & 0,09 & 0,04 & 0,04 & 0,06 & 0,23 & 0,06 & & Baixa \\
\hline & Total & - & 1,00 & 1,00 & 1,00 & 1,00 & 4,00 & 1,00 & 4,18 & \\
\hline
\end{tabular}

$I C=\lambda \max -n / n-1 \rightarrow I C=4,18-4 / 4-1 \rightarrow I C=0,18 / 3 \rightarrow I C=0,06$

$I R=I C / I R \rightarrow I R=0,06 / 0,90 \rightarrow I R=0,066 \rightarrow I R=6,6 \%$ 


\subsection{Vegetação}

A vegetação controla o escoamento superficial e a infiltração das águas no substrato. A perda da vegetação expõe o solo à erosão e favorece o escoamento superficial e a infiltração excessiva de água nos planos de cisalhamento, provocando a perda da coesão interna dos materiais.

Os principais efeitos adversos da vegetação são a sobrecarga e a atuação do vento. Tais efeitos podem ser controlados pela seleção efetiva das melhores espécies e, de modo alternativo, pela poda. Os principais benefícios são a evapotranspiração promovida tanto pela copa quanto pelas raízes e o reforço mecânico do solo nos primeiros $20 \mathrm{~cm}$.

Contribuindo no debate sobre a influência da vegetação nos movimentos de massa, alguns autores (por exemplo, USSELMANN 1969 apud BIGARELLA 2003) defendem a tese de que a floresta facilita a ocorrência de movimentos de massa. Através do sistema radicular pode-se aumentar a condutividade hidráulica e a saturação do manto de intemperismo.

A sobrecarga promovida pelas grandes árvores da floresta,aliada à declividade, pode tornar a vertente mais vulnerável à força da gravidade e, portanto, menos estável. Quando há sobrecarga na parte superior de um talude sem vegetação este fator torna-se ainda mais influente. Um exemplo clássico são os cortes de estrada mal executados, que além de não recuar a encosta até o ângulo de repouso, não retiram as árvores do topo do talude. Contudo, a vegetação exerce um importante papel na interceptação e retenção da água. Em média a vegetação intercepta de 10 a $15 \%$ da precipitação, mas pode chegar até $40 \%$ nas florestas tropicais, e quantidade significativa da água que chega ao solo é imediatamente evaporada (BIGARELLA 2003). A influência hidráulica de uma árvore na redução da umidade do solo pela absorção das raízes pode ser sentida a uma distância de até uma vez a altura da árvore (ARAUJO et al. 2005). Em geral, a vegetação pode influir positiva ou negativamente na estabilidade das encostas, porém, a retirada total da cobertura vegetal, conforme apontam diversos estudos (ARAUJO et al. 2005, BIGARELLA 2003), aumenta as taxas de erosão e influi incisivamente na instabilidade das vertentes.

Segundo ARAUJO et al. (2005), as funções da vegetação na estabilidade de encostas pode ser divididas em dois mecanismos: a) Mecanismo hidrológico:

- Interceptação pelas folhagens, absorção e evaporação, coma redução da taxa de infiltração;

- Raízes aumentam a rugosidade e a permeabilidade do solo, aumentando as taxas de infiltração;

- Diminuição da poropressão pela evaporação da umidade pelo sistema radicular;

- Redução da umidade do solo pode dar origem a rachaduras pelo ressecamento, resultando em uma maior capacidade de infiltração.

b) Mecanismo mecânico

- Reforço mecânico do solo promovido pelas raízes, diminuindo as tensões de cisalhamento; as partículas de solo são retidas pelas raízes e reduzem a susceptibilidade à erosão;

- Em caso de solos rasos, as raízes podem ancorar-se sobre um substrato firme, consistindo em um suporte para as massas de solo;

- O peso das árvores pode sobrecarregar a encosta, podendo favorecer movimentos gravitacionais, quando a sobrecarga atuar paralelamente, ou auxiliar a estabilidade,se atuar de modo perpendicular (não sendo o caso de vertentes íngremes);

- Forças dinâmicas transmitidas à encosta pela atuação do vento na vegetação.

Segundo DINIZ \& MATOS (1986), a composição florística, a fisionomia e as condições fisiográficas permitiram classificar as comunidades da área de estudo em: I - Comunidade das praias, II - Comunidade das falésias costeiras, III - Comunidade das ribeiras e dos vales abertos, IV - Comunidade das zonas áridas dos vales abruptos, coroamentos rochosos e cones vulcânicos, V - Comunidade das zonas semiáridas dos coroamentos rochosos e cones vulcânicos e por fim, VI - Comunidade das zonas subúmidas dos coroamentos rochosos e dos cones vulcânicos (Figura 9).

As classes IV (35,29\%) e V (41,7\%) apresentam maior representatividade no município; abrangem regiões com altitudes inferiores a $400 \mathrm{~m}$ correspondentes às extensas áreas árida litorânea, sublitorânea e semiárida (Tabela 8).

A ponderação das comunidades vegetais de acordo com o método AHP, no que tange à susceptibilidade a movimentos de massa, é apresentada na tabela 9 .

A classe VI apresenta maior capacidade de fixação do solo em relação às demais classes, em virtude da maior densidade de vegetação das comunidades das áreas subúmidas. 

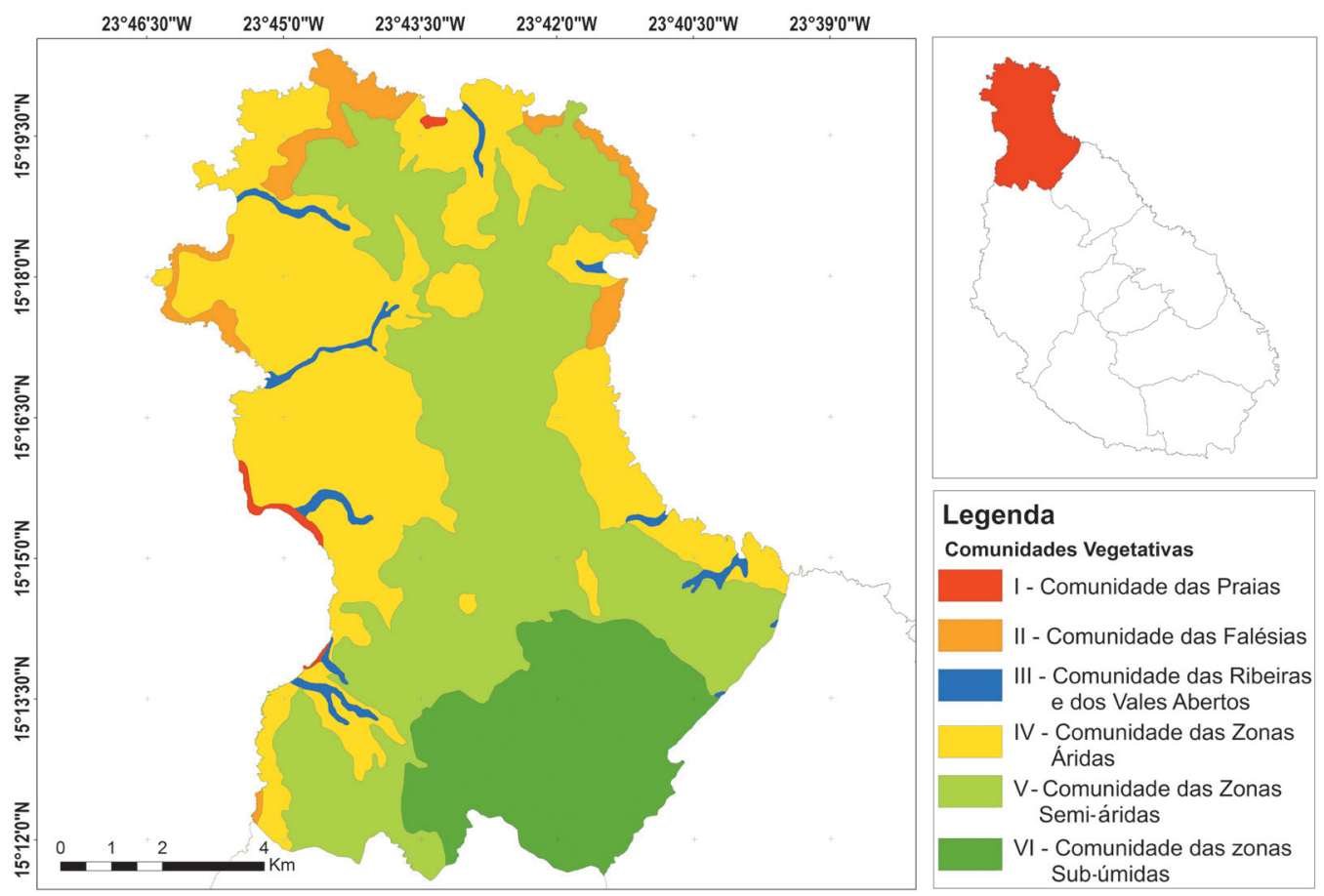

\section{Legenda}

Comunidades Vegetativas

I - Comunidade das Praias

II - Comunidade das Falésias

III - Comunidade das Ribeiras e dos Vales Abertos

IV - Comunidade das Zonas Áridas

V-Comunidade das Zonas Semi-áridas

$\mathrm{VI}$ - Comunidade das zonas Sub-úmidas

FIGURA 9 - Carta da vegetação do Município do Tarrafal (Extraído de DINIZ \& MATOS 1986).

TABELA 8 - Representatividade estatística das comunidades vegetais do Município de Tarrafal.

\begin{tabular}{cccc}
\hline Classes & Comunidade Vegetativa & Área $\left(\mathrm{km}^{2}\right)$ & Representatividade (\%) \\
\hline I & Comunidade das praias & 0,50 & 0,41 \\
II & Comunidade das falésias costeiras & 5,03 & 4,16 \\
III & Comunidade das ribeiras e dos vales abertos & 2,15 & 1,78 \\
IV & Comunidade das zonas áridas & 42,67 & 35,29 \\
V & Comunidade das zonas semiáridas & 50,41 & 41,70 \\
VI & Comunidade das zonas subúmidas & 20,14 & 16,66 \\
\hline
\end{tabular}

\subsection{Proximidade das vias}

Devido à influência exercida pela atividade humana, a rede viária representa um mecanismo deflagrador dos movimentos de massa, principalmente queda de blocos, já identificados em algumas regiões da Ilha do Santiago e também no próprio Município de Tarrafal. A tabela 10 mostra os pesos relativos associados à proximidade das vias (Figura 10).

\section{CARTA DE ZONEAMENTO DAS ÁREAS} SUSCEPTÍVEIS A MOVIMENTOS DE MASSA

A carta de zoneamento das áreas susceptíveis a movimentos de massa, gerada pelo cruzamento em SIG dos fatores naturais e antrópicos segundo o método AHP, é apresentada na figura 11.

Trabalhos de campo realizados após o zoneamento puderam identificar cicatrizes de quedas de blocos e áreas com elevada probabi- 
TABELA 9 - Ponderação AHP em função das classes de comunidade vegetal identificadas no Município de Tarrafal (Extraído de DINIZ \& MATOS 1986). CFS é a Capacidade de Fixação do Solo.

\begin{tabular}{|c|c|c|c|c|c|c|c|c|c|c|}
\hline & $C V-V I$ & $C V-V$ & $C V-I V$ & CV-III & $C V-I I$ & $C V-I$ & & & & \\
\hline$C V-V I$ & 1,00 & 3,00 & 4,00 & 6,00 & 7,00 & 9,00 & & & & \\
\hline$C V-V$ & 0,33 & 1,00 & 2,00 & 3,00 & 5,00 & 7,00 & & & & \\
\hline$C V-I V$ & 0,25 & 0,50 & 1,00 & 2,00 & 3,00 & 5,00 & & & & \\
\hline$C V-I I I$ & 0,17 & 0,33 & 0,50 & 1,00 & 2,00 & 3,00 & & & & \\
\hline$C V-I I$ & 0,14 & 0,20 & 0,33 & 0,50 & 1,00 & 2,00 & & & & \\
\hline$C V-I$ & 0,11 & 0,14 & 0,20 & 0,33 & 0,50 & 1,00 & & & & \\
\hline \multirow[t]{2}{*}{$X w$} & 2,00 & 5,18 & 8,03 & 12,83 & 18,50 & 27,00 & & & & \\
\hline & $C V-V I$ & $\mathrm{CV}-\mathrm{V}$ & CV-IV & CV-III & CV-II & $C V-I$ & Total & $w$ & $\lambda \operatorname{Max}$ & $C F S$ \\
\hline$C V-V I$ & 0,50 & 0,58 & 0,50 & 0,47 & 0,38 & 0,33 & 2,76 & 0,46 & & $\begin{array}{l}\text { Muito } \\
\text { Elevada }\end{array}$ \\
\hline$C V-V$ & 0,17 & 0,19 & 0,25 & 0,23 & 0,27 & 0,26 & 1,37 & 0,23 & & Elevada \\
\hline CV-IV & 0,13 & 0,10 & 0,12 & 0,16 & 0,16 & 0,19 & 0,85 & 0,14 & & $\begin{array}{l}\text { Elevada } \\
\text { Moderada }\end{array}$ \\
\hline CV-III & 0,08 & 0,06 & 0,06 & 0,08 & 0,11 & 0,11 & 0,51 & 0,08 & & Moderada \\
\hline CV-II & 0,07 & 0,04 & 0,04 & 0,04 & 0,05 & 0,07 & 0,32 & 0,05 & & $\begin{array}{c}\text { Baixa } \\
\text { Moderada }\end{array}$ \\
\hline$C V-I$ & 0,06 & 0,03 & 0,02 & 0,03 & 0,03 & 0,04 & 0,20 & 0,03 & & Baixa \\
\hline Total & 1,00 & 1,00 & 1,00 & 1,00 & 1,00 & 1,00 & 6,00 & 1,00 & 6,20 & \\
\hline
\end{tabular}

$I C=\lambda \max -n / n-1 \rightarrow I C=6,20-6 / 6-1 \rightarrow I C=0,20 / 5 \rightarrow I C=0,04$

$I R=I C / C A \rightarrow I R=0,04 / 1,24 \rightarrow I R=0,032 \rightarrow I R=3,2 \%$
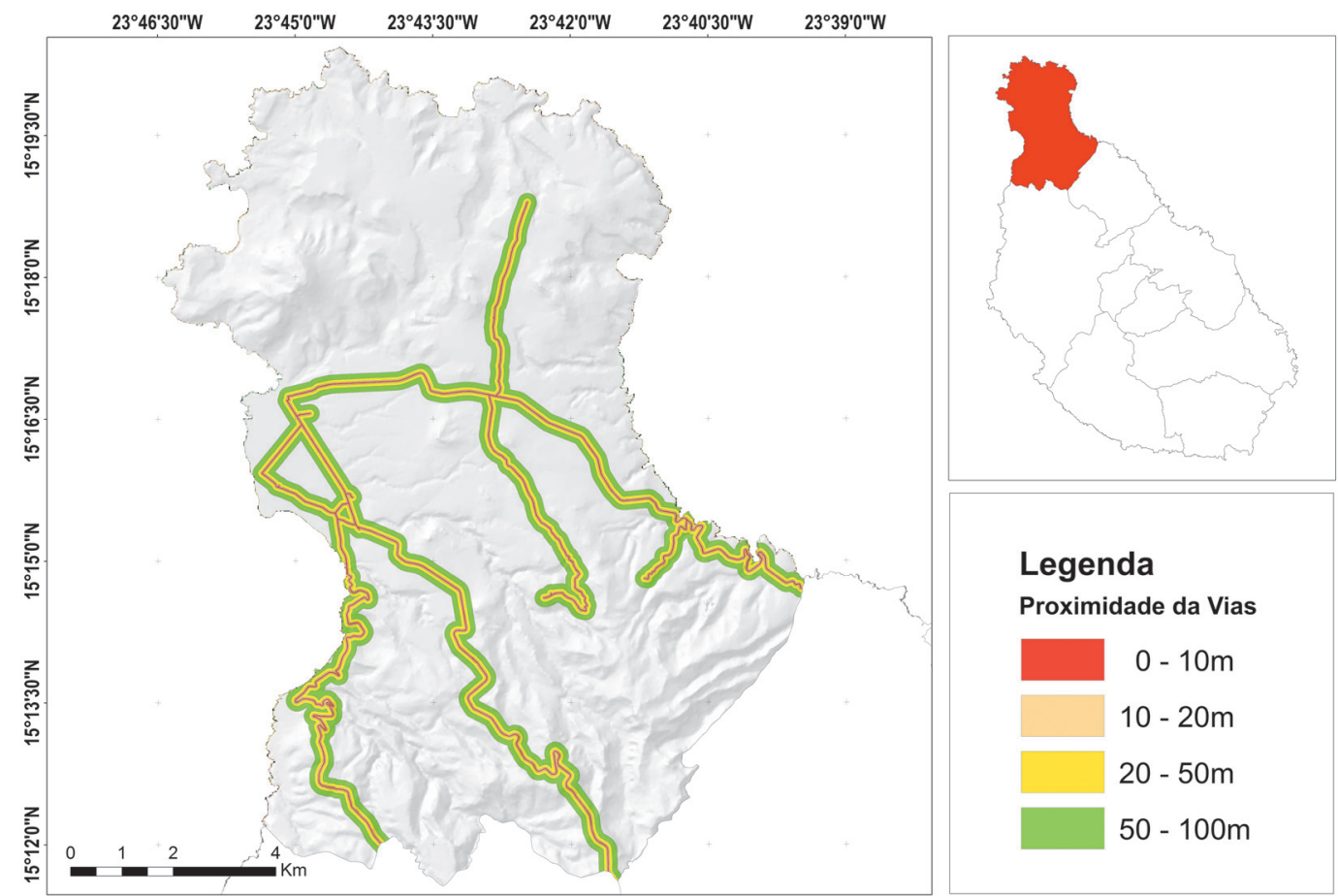

FIGURA 10 - Carta de proximidade das vias do Município de Tarrafal. 
TABELA 10 - Ponderação AHP em função da proximidade das vias.

\begin{tabular}{|c|c|c|c|c|c|c|c|c|}
\hline Metros & 10 & 20 & 50 & 100 & & & & \\
\hline 10 & 1,00 & 2,00 & 5,00 & 7,00 & & & & \\
\hline 20 & 0,50 & 1,00 & 3,00 & 5,00 & & & & \\
\hline 50 & 0,20 & 0,33 & 1,00 & 3,00 & & & & \\
\hline 100 & 0,14 & 0,20 & 0,33 & 1,00 & & & & \\
\hline$X w$ & 1,84 & 3,53 & 9,33 & 16,00 & & & & \\
\hline Metros & 10 & 20 & 50 & 100 & Total & $w$ & $\lambda \max$ & Susceptibilidade \\
\hline 10 & 0,54 & 0,57 & 0,54 & 0,44 & 2,08 & 0,52 & & Muito Elevada \\
\hline 20 & 0,27 & 0,28 & 0,32 & 0,31 & 1,19 & 0,30 & & Elevada \\
\hline 50 & 0,11 & 0,09 & 0,11 & 0,19 & 0,50 & 0,12 & & Moderada \\
\hline 100 & 0,08 & 0,06 & 0,04 & 0,06 & 0,23 & 0,06 & & Baixa \\
\hline T total & 1,00 & 1,00 & 1,00 & 1,00 & 4,00 & 1,00 & 4,10 & \\
\hline
\end{tabular}

$I C=\lambda \max -n / n-1 \rightarrow I C=4,10-4 / 4-1 \rightarrow I C=0,10 / 3 \rightarrow I C=0,03$

$I R=I C / I R \rightarrow I R=0,03 / 0,90 \rightarrow I R=0,037 \rightarrow I R=3,7 \%$
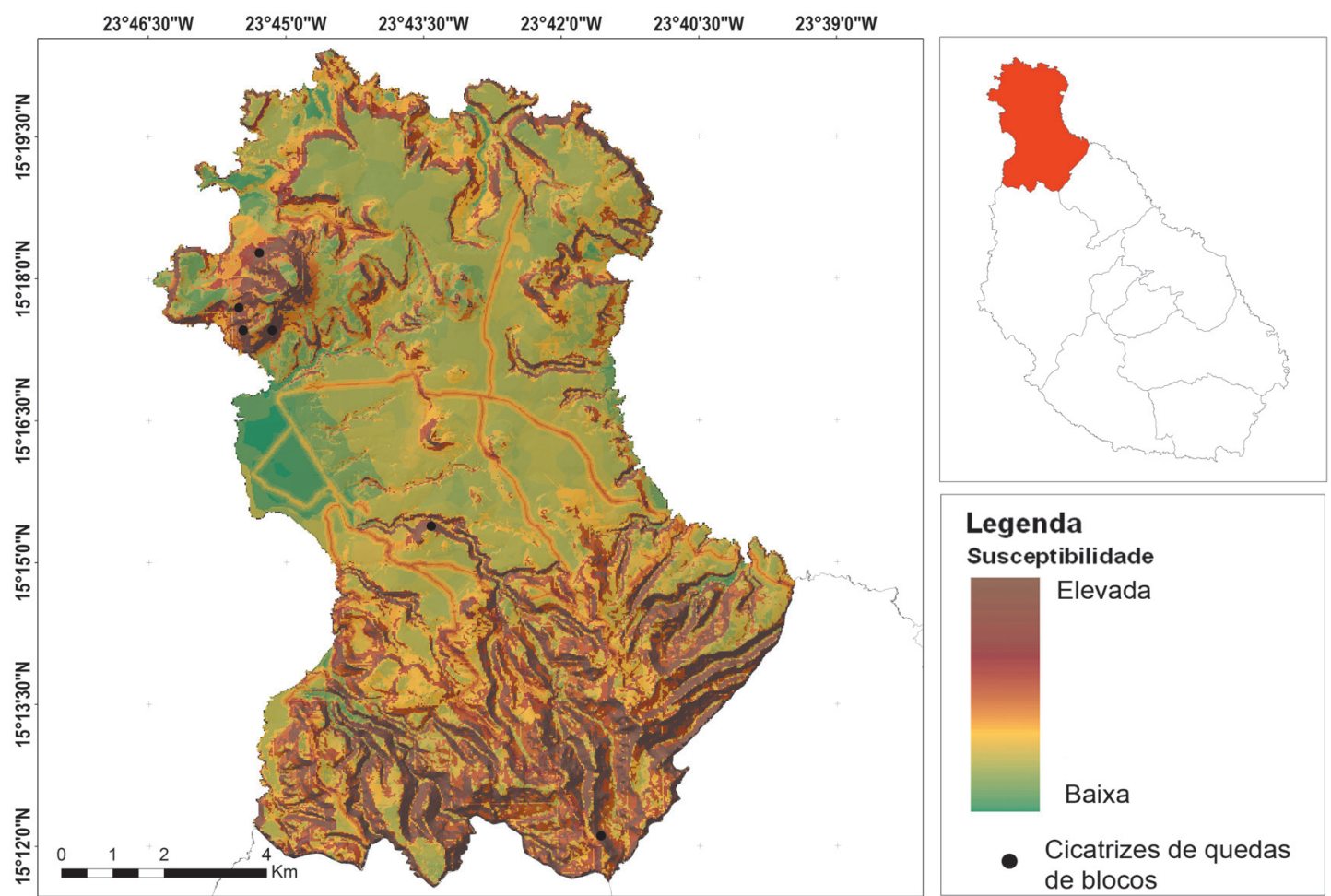

\section{Legenda}

Susceptibilidade

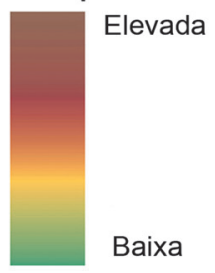

Cicatrizes de quedas de blocos

FIGURA 11 - Carta de susceptibilidade a movimentos de massa do Município de Tarrafal. 
lidade de ocorrência dos processos em análise (Figura 12).

Constata-se que as áreas com maior susceptibilidade são aquelas localizadas na região sul do município, ao longo das vertentes da cadeia montanhosa da Serra Malagueta (Figura 11). Registramse também altos índices ao longo da Ribeira Grande e nas vertentes escarpadas do Monte Graciosa. Essas áreas apresentam as maiores amplitudes altimétricas do município, densidade de fraturas relativamente elevada e escarpas e cristas com elevado índice de declividade, fatores que favorecem movimentos de massas do tipo queda de blocos.

Em contrapartida, as zonas de baixa susceptibilidade correspondem àquelas aptas à urbanização e à construção de infraestrutura, uma vez que apresentam uma elevada estabilidade geotécnica. Essas zonas compreendem a extensa área plana situada ente a Cidade do Tarrafal e o aglomerado de Chão Bom, Achada Tomás, Achada Boi e Achada Bilim.

\section{CONCLUSÕES}

A metodologia adotada para a elaboração da carta de susceptibilidade a movimentos de massa do Município de Tarrafal mostra-se muito promissora, uma vez que permite uma análise multicriterial dos fatores naturais e antrópicos. A partir desse zoneamento foi possível identificar em campo as áreas mais críticas do ponto de vista geotécnico.

As ferramentas de SIG permitiram agrupar e classificar áreas homogêneas em relação ao potencial à susceptibilidade a movimentos de massa com elevada eficácia.

A presente análise mostra-se uma prática imprescindível para os estudos geotécnicos e, consequentemente, na tomada de decisões em nível municipal e no âmbito da defesa civil, podendo subsidiar a elaboração de outros tipos de cartografia, como a de perigo e de risco.

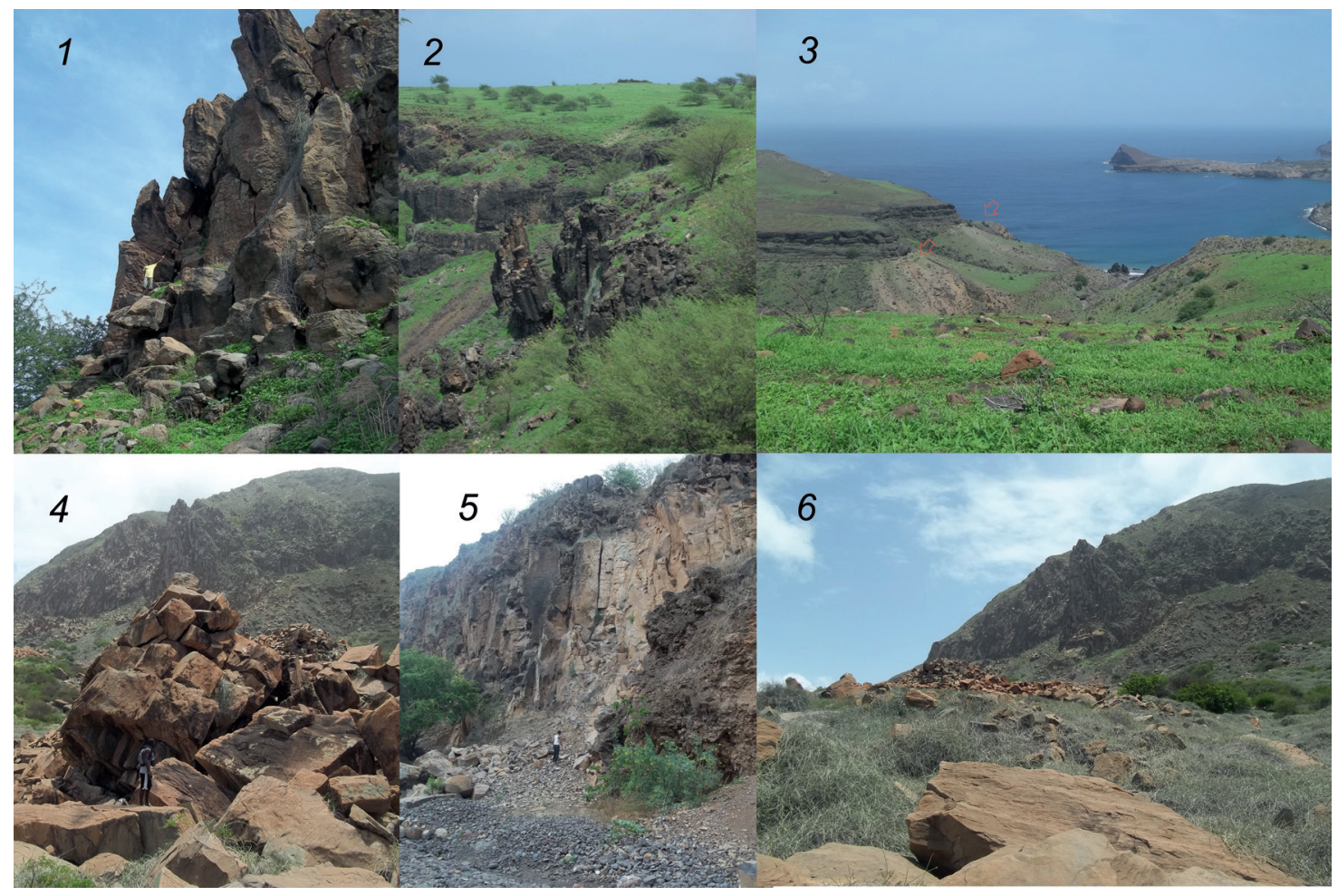

FIGURA 12 - Identificação de áreas de elevada susceptibilidade a queda de blocos.1-2: Blocos e matacões com elevado grau de fraturamento em áreas de declive acentuado (Monte Graciosa); 3: Queda de blocos ao longo da vertente (Baía de Fazenda); 4-6: Depósito de blocos e matacões resultado de desmoronamento (vertente norte de Monte Graciosa); 5: Basaltos com disjunção colunar, apresentando elevado grau de fraturamento em áreas de declive acentuado (Bacia de Ribeira Grande). 


\section{REFERÊNCIAS BIBLIOGRÁFICAS}

AMARAL, I. 1964. Santiago de Cabo Verde. A Terra e os homens. Junta de Investigações do Ultramar, Lisboa, 444 p.

ARAUJO, G.H.S.; ALMEIDA, J.R.; GUERRA, A.J.T. 2005. Gestão Ambiental de Áreas Degradadas. Editora Bertrand Brasil, Rio de Janeiro, $320 \mathrm{p}$.

BIGARELLA, J.J. 2003. Estrutura e origem das paisagens tropicais e subtropicais. Editora da UFSC, Florianópolis, 1026 p.

CORONADO, J.A. 2006. Avaliação da suscetibilidade de deslizamentos por meio do uso do Sistema de Informação Geográfica: Aplicação em uma área do eixo Cafeteiro Colombiano. Departamento de Engenharia Civil, Universidade de Brasília, Brasília, Dissertação de Mestrado, 92p.

DGOTDU - DIRECÇÃO GERAL DO ORDENAMENTO DO TERRITÓRIO E DESENVOLVIMENTO URBANO. 2003. Dados Cartográficos. Praia, Cabo Verde.

DINIZ, C.A.; MATOS, D.C. 1986. Carta de zonagem agro-ecológica e da vegetação de Cabo Verde - Ilha de Santiago. Lisboa, Instituto de Investigação Científica Tropical.

GARCIA, R.; ZÊZERE, J.L. 2003. Avaliação de riscos geomorfológicos: Conceitos, Terminologia e Métodos de Análise. In: SEMINÁRIO RECURSOS GEOLÓGICOS, AMBIENTE E ORDENAMENTO DO TERRITÓRIO, 3,Vila Real, Livro de Actas, 299-308.

MUÑOZ, V. 2005. Análise comparativa de técnicas de inferência espacial para identificação de unidades de suscetibilidade aos movimentos de massa na região de São Sebastião. INPE, Monografia de Especialização do XVIII Cur- so Internacional em Sensoriamento Remoto e Sistemas de Informação Geográfica, São José dos Campos, $61 \mathrm{p}$.

OLIVEIRA, V.P. 2011. Indicadores biofisicos de desertificação, Cabo Verde/África. Mercator, 10(22): 147-168.

PEREIRA, A.; AZEVEDO, J.; VICTÓRIA, S.; CUNHA, P.; PEREIRA, L.; VICENTE, A. 2008. Structural interpretation of Santiago Island (Cape Verde) based on remote sensing techniques.Geophysical Research Abstracts, EGU General Assembly, Vol. 10, 4p.

ROSA, R. 1996. Metodologia para zoneamento de bacias hidrográficas utilizando produtos de Sensoriamento Remoto e integrados por Sistema de Informação Geográfica.In: INPE, SIMPÓSIO BRASILEIRO DE SENSORIAMENTO REMOTO, 8, Salvador, Anais, 363-368.

SAATY, T.L. 1991 Método de Análise Hierárquica. McGraw-Hill, Makron, São Paulo, 367 p.

SABINO, A.A. 1991. Contribuição das águas pluviais para o abastecimento da Cidade da Praia. INIDA, Cabo Verde, 8 p.

SERRALHEIRO, A. 1976. A Geologia da Ilha de Santiago (Cabo Verde). Universidade de Lisboa, Tese de Doutorado, 218 p.

SESTINI, M. 1999. Variáveis geomorfológicas no estudo de deslizamentos em Caraguatatuba-SP utilizando imagens TM-Landsat e SIG. Instituto Nacional de Pesquisas Espaciais INPE, São José dos Campos, Dissertação de Mestrado, $140 \mathrm{p}$.

SILVA, D.M. 2007. Aplicação do método AHP para avaliação de projectos industriais. Dissertação de Mestrado, PUC-RJ, Rio de Janeiro, 128 p.

Endereço dos autores:

Herculano Spínola - Bairro Colhe-Bicho, Cidade do Tarrafal, Santiago, Cabo Verde. E-mail: platiny. spinola@gmail.com

Sónia Victória - Universidade de Cabo Verde, Departamento de Ciência e Tecnologia, Campus do Plamarejo, CP 279, Praia, Santiago, Cabo Verde.E-mail: sonia.silva@docente.unicv.edu.cv 